\title{
Force loading of wagon during interaction of truck and bodywork in curves paths
}

\author{
Ermolenko Igor Yurievich \\ Dept. of Wagons and Wagon economy \\ Irkutsk State Transport University \\ Irkutsk, Russia \\ lord2171@mail.ru
}

\author{
Zheleznyak Vasiliy Nikitovich \\ Dept. of Wagons and Wagon economy \\ Irkutsk State Transport University \\ Irkutsk, Russia \\ zheleznyak_vn@irgups.ru
}

\author{
Martynenko Lyubov Victorovna \\ Dept. of Wagons and Wagon economy \\ Irkutsk State Transport University \\ Irkutsk, Russia \\ liuba.martinenko@yandex.ru
}

\begin{abstract}
This article examines the reasons for gatherings of mountain areas; the relationship of malfunctions of the technical systems of the wagon; proposals for the detection and elimination of the causes of their formation
\end{abstract}

Keywords-axle box; automatic coupling; thrust plate; complex technical systems upgraded; draw clamp; restrictive path; security posts

\section{INTRODUCTION}

Bogie model 18-100 is a very reliable technical device which operates faultlessly over 50 years under freight cars. Today on the basis of this trolley features, there is a lineup of products-for example, shopping carts: $18-578$; 18-194-1; 189836; 18-9855 [1].

Despite the simplicity and versatility of the trolleys of the 18-100 lineup, they are not without flaws. These deficiencies affect the dynamics of movement of wagons in general, especially in small radius curves. In these sections, there is a danger of avalanche paths. In these sections, there is a danger of derailing of the rolling stock, which always requires a thorough analysis of the type of goods and the correctness of the wagon; speed mode; profile path [2].

On the basis of the foregoing problems, the authors developed criteria for assessing the safety of wheel and rail interaction, curves pass route, as well as the impact of the technical condition of the chassis rolling on traffic safety, which is always relevant [3].

Since 2004, OJSC NPK Uralvagonzavod has constantly pursued comprehensive activities aimed at improving the characteristics of durability, reliability, durability of all generations, including cluster bearings [4].

This set of measures is aimed at priority transport reliability and increasing the security of the transportation system of the country and at solving these problems, the road network using security positions.

Figure 1 shows an example of the location of the security positions at the network of East-Siberian railroad (ESRR) mountain terrain.

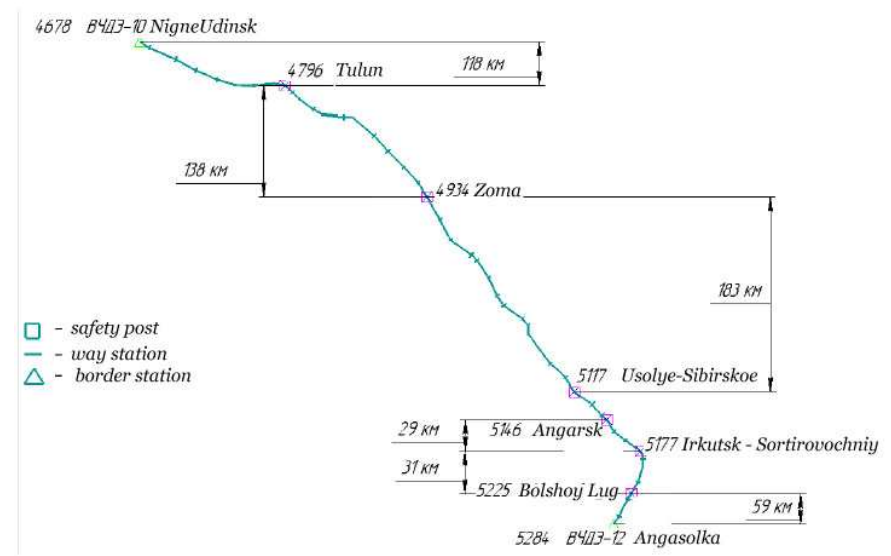

Fig. 1. Location of security positions in the mountain terrain crossover network

The work of security posts within a day is reduced to tables with separate indicators for: wheel pairs; axlebox knots; trolleys; body; a draw-buffing gear. [5].

Fig. 2-3 show examples of graphical representations of the detected faults on the security post for the past two years on axle box and automatic coupling. The data are obtained after verification of the averaged according to the results of examination positions of technical inspection items. A graphical representation of the information allows the analysis and formulation of a set of measures aimed at prevention of negative events. 

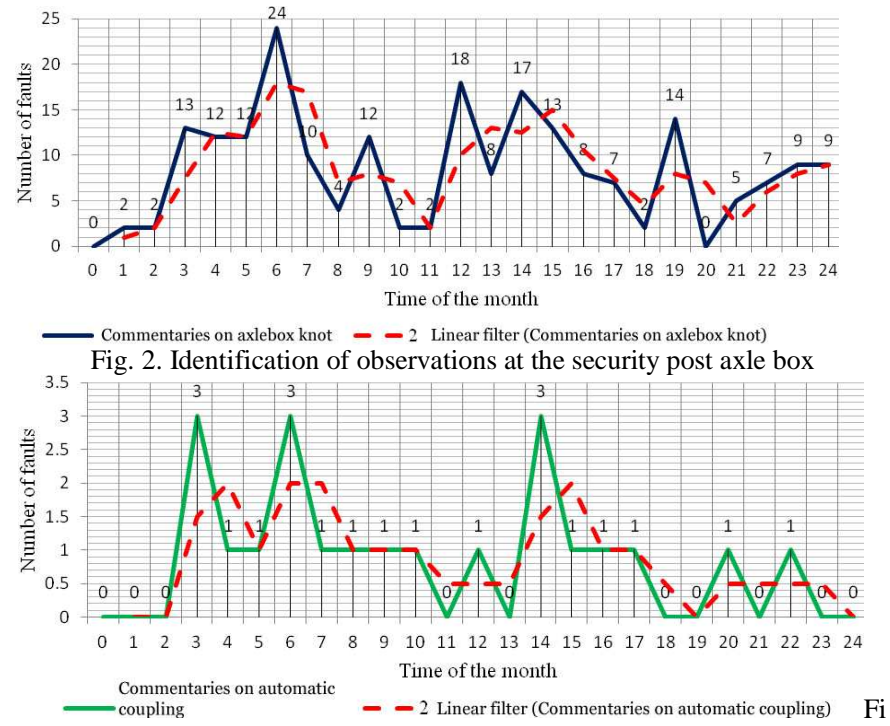

g. 3. Identification of observations at the security post automatic coupling type SA-3

One should pay particular attention to the link reliability with node uptime axle parts and units of chains of wagons, taking into account the performance of security positions and systems of automated visual inspection of technical characteristics of the rolling stock "Tehnovizor" [5].

\section{Methodology}

Previously we saw cracks axle units and automatic coupling separately from each other, believing that these are different events in which there is no obvious sign of their relationship.

In 2017, a number of gatherings of freight wagons on one distance path ESRR have prompted us to undertake an analysis of the results of the investigation for several years.

The main reason for the possible vanishing distance "Kedrovaya" is a combination of failures of the wagon, ways and state violations of driving trains.

Cracks were on the installed center plate, spring grouping, axle box assemblies with SA-3 coupler failures that in the interrelation led to mudslides when passing through the mountain terrain profile path (fig. 4).
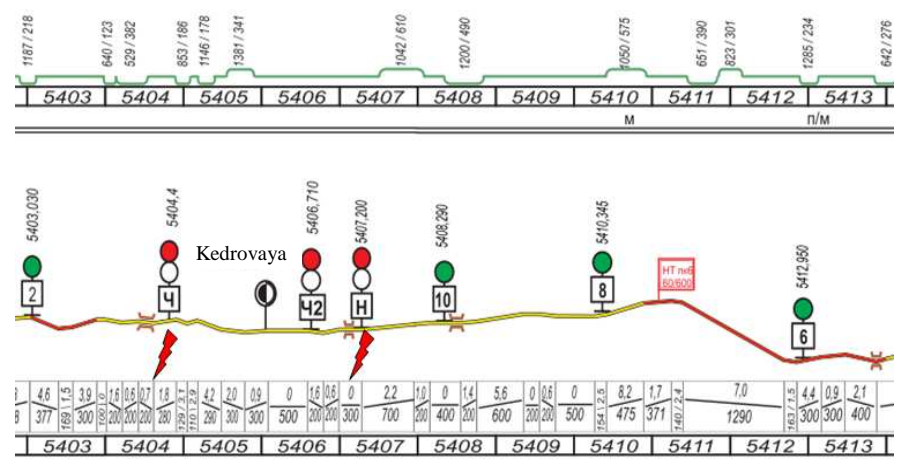

Fig. 4. Modal map of driving freight trains on the section "Kedrovaya"
The path to the station "Tanhoy-Kedrovaya" refers to the mountain terrain. To assess the mutual influence of SA node 3 , wagons pass on curves plots path, check the value of the angles of lateral deflections of the longitudinal axis of the wagon of coupler axle mentioned above. Let us consider the famous theoretical framework design scheme of passage of two coupled cars curves [6].

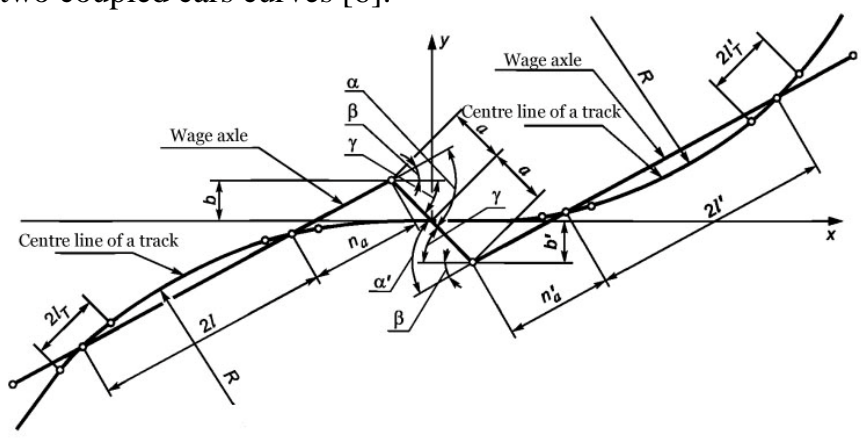

Fig. 5. Estimated map of two coupled cars curves

If you fit the curves of the track sections, the coupler housing is able to move horizontally (across the way) to $11^{0}$ $12^{0}-13^{0}$ each way.

Design and calculation of shock-traction devices are checking passage wagons on the S-curve. Criteria for payment are accepted corners transverse deflections of the longitudinal axis coupler- $\gamma, \beta$-axis, where $\alpha$ and $\alpha^{\prime}$ - corners between axes of automatic coupling and the longitudinal axis of the wagons, which are defined by the equations:

$$
\begin{aligned}
& \alpha=\beta+\gamma \\
& \alpha^{\prime}=\beta^{\prime}+\gamma \\
& \beta=\operatorname{arctg} \frac{l+n_{a}+a}{R} \\
& \beta^{\prime}=\operatorname{arctg} \frac{l^{\prime}+n^{\prime}+a}{R^{\prime}} \\
& \gamma=\arcsin \frac{b+b^{\prime}+\xi}{2 a} .
\end{aligned}
$$

Specified design parameters are laid down in the technical documentation for the type of the wagon under established model SA-3 according to GOST 32885 and GOST 3475 of restrictive path.

The authors received the calculated coordinates $\left(\alpha, \alpha^{\prime}\right)$ that intersect at the point made in the restrictive path for the articulated types of supports front: UP1; UP2; UP3 cars with a model SA-3 coupler. The restrictive path with lock type UP1 is in fig. 6 [7]. 


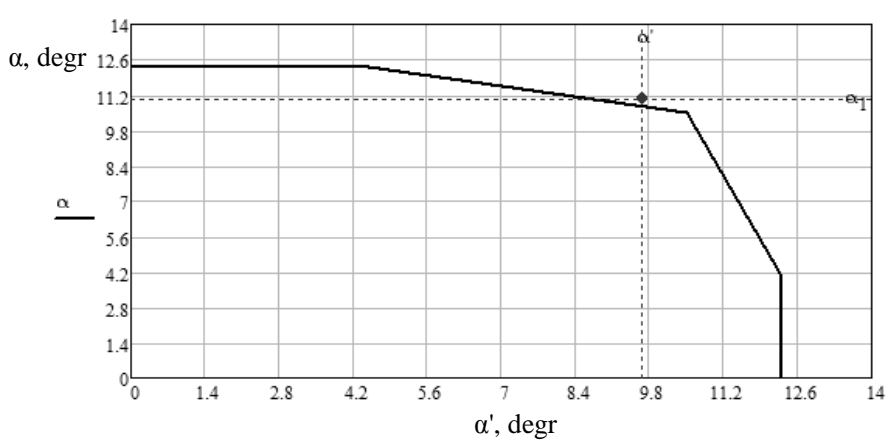

Fig. 6. The position of the point of the passage linking cars with a gathering on a stretch of Kedrovaya-Tankhoy

If the point lies within the circuit, passage of wagons on the curved sections is provided [8]. If the outline of the point is the need to adjust the calculation, let us checkup serviceability of the coupler casing and stop UP1.

Reconditioned palm UP1 provides normal job corps SA-3 shank (R130) in contact with the shell hard plates (R150).

Mirroring the stain from the contact surfaces on the radial thrust plate must be arranged strictly according to the axis of symmetry. Such coupling surfaces confirm proper operation of the SA-3 coupler in general (fig. 7.a).

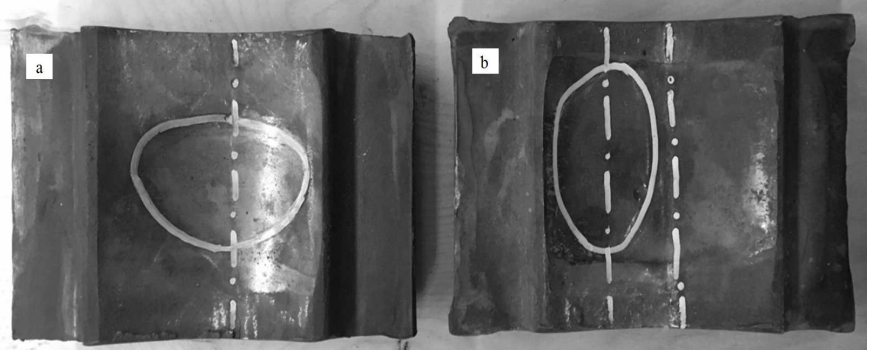

Fig. 7. Contact patches on a hard plate: (a) symmetrical; (b) with the shift to the left

If the contact patch on the hard plate has an offset from the axis of symmetry (right-left, fig. 7.b), one must check for smooth rotation between corps SA-3 shock window outlets (as far as it will go in vertical facets window UP1) (fig.8).

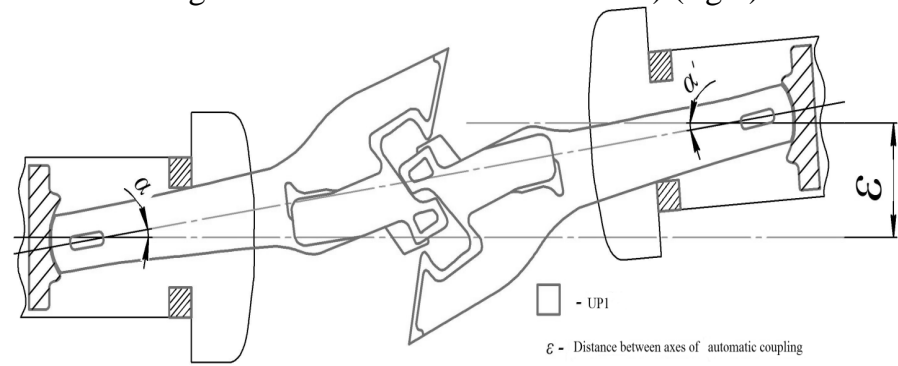

Fig. 8. The position of the vertical supports in UP1 and axles wagons

It is possible that the contact surfaces (R150 and R130) become nonoperative and have defects that restrict the mobility of the coupling in the horizontal plane (poor surface condition after repair of the shank).
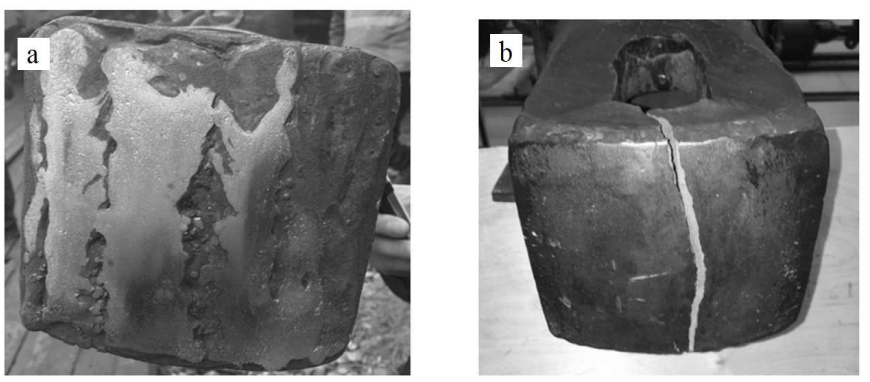

Fig. 9. Coupler shank: (a) shank coupler housings with vanishing; (b) shank, renovation

Permissible shaft deflection angles depend on the position of the towing wedge in profile reduced cone holes under the yoke wedge forming an angle of $\alpha=22^{0}-24^{0}-26^{0}$ (fig. 10).

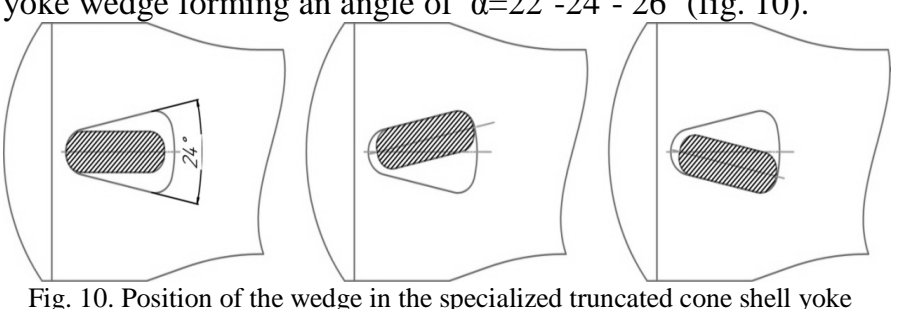

Fig. 10. Position of the wedge in the specialized truncated cone shell yoke

\section{RESULTS}

Determination of the technical condition of the coupler under the current inspection includes verification of wedge yoke; exit of the shell shock of the socket as far as it will go to a head coupler; check of the lack of clearance between the bottom of the chassis of the absorbing apparatus and a pulling clamp.

Control over the position of angular deviation of the coupler tail relative to the central axis of the wagons in operation is difficult.

Since the shell coupler is able to move horizontally (across the $11^{0}-12^{0}-13^{0}$ path in each direction), any inspection during the day and at night of these labels can be controlled visually, including an automated system "Tehnovizor" with the presence of technical vision (fig. 11) [5].
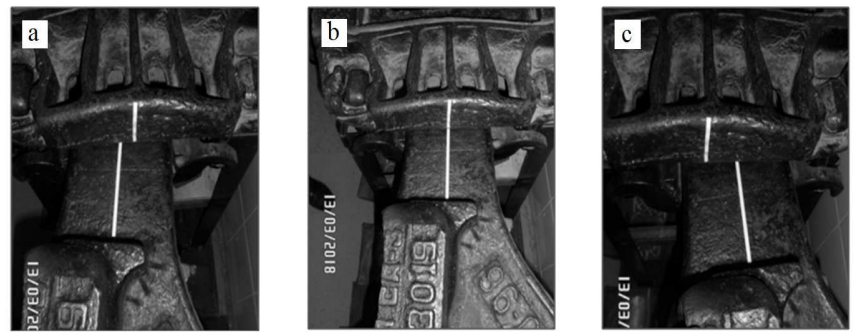

Fig. 11. Possible provisions of coupler: (a) left-skewed; (b) symmetrical; (c) right-skewed

Figure 11 represents the real picture of assessing the possibility of detection and prevention at an early stage of destruction of axle parts site, which we have fully investigated as parameters KTSM records.

Track section, Baikalsk - Pereemnaya, on which cargo moves over 1 hour 9 minutes in 19 wagon with the head whole; left wheel 4 facing the wheel comes with the excess 
temperature of $5^{\circ}-10^{\circ}-15^{\circ} \mathrm{C}$, relative to other (three) axle that KTSM «does no see». Table 1 shows the printing system for ASK PS supervision of the wagon, which is transformed into the chart (fig. 12), the zone of control equipment KTSM.

TABLE I. PRINTING FROM THE SYSTEM ASK PS

\begin{tabular}{|l|l|c|c|c|c|c|c|c|c|}
\hline \multicolumn{1}{|c|}{ Item } & Time & 1L & 1R & 2L & 2R & 3L & 3R & 4L & 4R \\
\hline Baikalsk & $15: 14$ & $7^{\circ}$ & $12^{\circ}$ & $6^{\circ}$ & $10^{\circ}$ & $10^{\circ}$ & $11^{\circ}$ & $18^{\circ}$ & $10^{\circ}$ \\
\hline Vidrino & $15: 40$ & $10^{\circ}$ & $14^{\circ}$ & $8^{\circ}$ & $12^{\circ}$ & $12^{\circ}$ & $11^{\circ}$ & $21^{\circ}$ & $9^{\circ}$ \\
\hline Kedrovaya & $16: 02$ & $8^{\circ}$ & $14^{\circ}$ & $7^{\circ}$ & $12^{\circ}$ & $11^{\circ}$ & $12^{\circ}$ & $25^{\circ}$ & $12^{\circ}$ \\
\hline Tanhoy & $16: 13$ & $10^{\circ}$ & $15^{\circ}$ & $10^{\circ}$ & $13^{\circ}$ & $12^{\circ}$ & $12^{\circ}$ & $34^{\circ}$ & $12^{\circ}$ \\
\hline Pereemnaya & $16: 23$ & $8^{\circ}$ & $14^{\circ}$ & $8^{\circ}$ & $11^{\circ}$ & $11^{\circ}$ & $11^{\circ}$ & $114^{\circ}$ & $11^{\circ}$ \\
\hline
\end{tabular}

During the movement of the left wheel comes with dual temperature increases throughout the route, and the temperature rise during the last minutes of the 15-20 movement, going on to surge of 114 degrees and complete axle by jamming the site. Inspection showed that the inner ring of the bearing collapsed and partially burned.

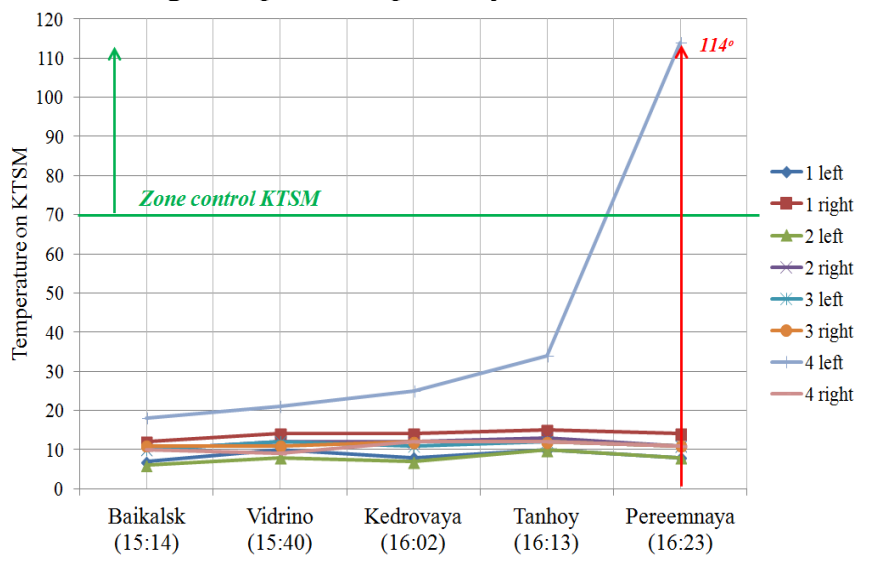

Fig. 12. Temperature rise in the axle box

\section{CONCLUSION}

Cracks, ruptures of internal and external rings appear mostly in operation when the wagon is operated primarily on difficult sections of mountainous terrains (fig.12).

Causes of appearance defects and destruction in the axlebox may be: lozenging of bogie side frames (18-100 to 30 $\mathrm{mm})$, the crooked wheel pair axle;

- offset to another (UP1) in the extreme corner position of shell shank SA-3 on the hard plate (up to $13^{0}$ to the right or left);

- distortions of a series of rollers in the front and rear, radial bearings due to the fact that the axis of symmetry of wheel pair "aims to" take some angular deviation;

- prestressing of spring grouping promotes filling up the body and extra load on the axle box;

- tapered wear center plate arrangement affects the position of the centre of the gravity wagon;
- the position of coordinates of the calculated point $\left(\alpha, \alpha^{\prime}\right)$ on the border of the restrictive path indicates jamming of the corps SA-3 and transverse forces, constantly pressing the comb to the lateral surface of the rail, leading to derailing.

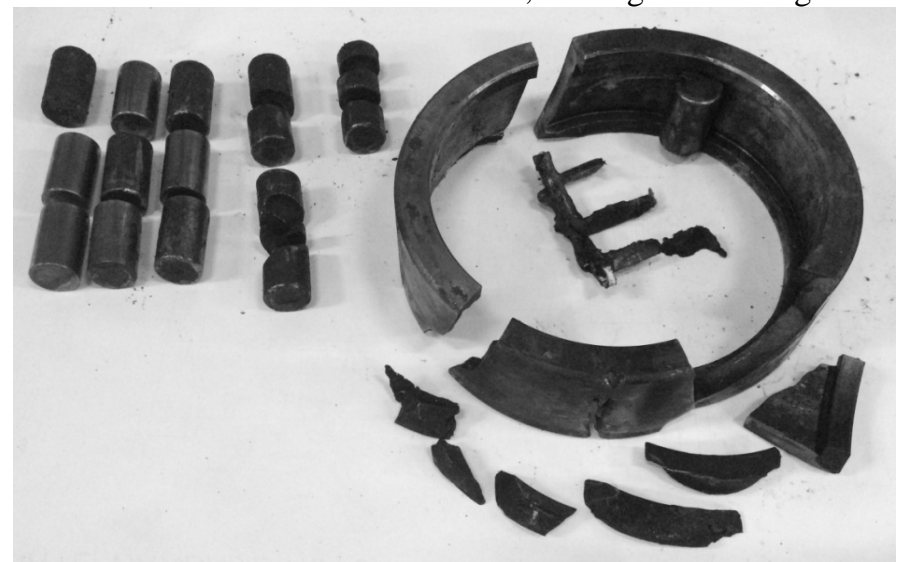

Fig. 13. Elements of a destroyed bearing

A modern railroad of main roads of Russia has a margin and is able to ensure the safety of trains.

Found wreckage and crash are closely associated with gathering mechanism rails [9]. Timely analysis of the causes and mechanisms of gathering wheels to the rails is also required for objective comprehensive assessment of a current status of traffic safety of trains.

\section{Acknowledgement}

The authors of the paper expressed their particular point of view, using materials and experience that were kindly offered and gained in joint investigations.

\section{References}

[1] D.N. Losev, 2016. Cars trucks "Barber" results exploitation. Journal «Wagons and wagon economy», Vol. 4(48), pp. 8-9.

[2] Yu.S. Romen, L.A. Mutinshtein, L.I. Neverova, Influence of longitudinal forces in trains on the danger of derailing cars depending on their load. Journal «Transport of the Russian Federation», Vol. 3(46), pp. 64-68.

[3] A.A. Shvets, K.I. Zheleznov, A.S. Akulov, A.N. Zabolotny, E.V. Chabanjuk, Some aspects of the definition of sustainability of empty wagons from squeezing their longitudinal forces in freight trains. Bulletin of Dnepropetrovsk National University of railway transport, Vol. 4(58), pp. 175-185.

[4] T.V. Ivanova, D.G. Nalabordin, Score pre-failure condition states of axle box freight wagons. Journal «Wagons and wagon economy», Vol. 1(49) , 2017, pp. 46-47.

[5] A.V. Lobova, An analytical assessment of the work of the security positions at carload operational Depot Irkutsk-Sortirovochny. Transport security and complex technical systems through the eyes of youth, IrGUPS, Irkutsk, pp. 117-123.

[6] A.S. Adadurov, R.Yu. Bushuev, A.I. Dolgij, A.V. Hatlamandjiyan, Post integrated control as an innovative approach to the diagnosis of chassis the wagon. Journal «Wagons and wagon economy», Vol. 4(44), 2015, pp. 24-27.

[7] V.N. Koturanov, Wagons. Design principles and technical solutions expertise. Marshrut, Moscow, 2005.

[8] GOST 33211-2014. Freight wagons. The requirements for durability and dynamic qualities. Standartinform, Moscow, 2016. 
[9] Yu.P. Boronenko, Calculation of automatic coupling device SA-3 installed on platform model 23-469. NVC «Vagony», St. Petersburg, 2004, pp. 1-14.
[10] V.S. Lysyk, Causes and mechanism of derailment rail wheels. The problem of wheel and rail wear, Transport. Moscow, 1997. 